\title{
The influences of normative information on human judgmental processes*
}

\section{JOHN GORMLY \\ Rutgers, The State University, New Brunswick, N.J. 08903}

Ninety-seven Ss were exposed to bogus information of how others rated politicians for the intelligence required and social usefulness of the profession. Four dependent measures of this situation were investigated: conformity toward the bogus information, attitude change, restructuring the meaning of the situation, and awareness of the deception manipulations. The effectiveness of peer-group sources for influencing judgments in college students was demonstrated. The data indicated substantial attitude change and no significant restructuring of the situation. The pattern of findings supports a cognitive-anchoring interpretation for the influence of normative information on judgmental processes. There was no indication that any $S$ was suspicious of the methods employed.

Human judgmental processes are perennially interesting to researchers in psychology. The following study investigated the effects of group norms on judgmental processes, using an experimental procedure developed by Asch and his associates (Asch, Block, \& Hertzman, 1940). People are given a list of 10 professions and are asked to rank the professions according to the amount of intelligence required of members of the profession and the social usefulness of the profession. They are told that another group has already ranked the professions, and false norms are given.

Three issues relevant to the dynamics of human judgments are examined here: the effects of the prestige of the source of the alleged norms on the extent of change in judgments, the significance of judgmental change on the evaluation of politics, and restructuring the meaning of the situation after false norms are given.

Although social conformity is a pervasive phenomenon, it is often not clear what specifically has occurred when an individual changes his judgment. Change in the ratings of politicians could be merely the restatement of group norms without any change in the person's judgment about politicians, or the change in ratings could indicate a change in the person's evaluation of politicians, or, as Asch has suggested (1948; Asch, Block, \& Hertzman, 1940), change in ratings of politicians following group norms could indicate a redefinition of the group of politicians being rated.

Asch and his associates reported that, in the ranking of politicians after being given false norms, Ss changed their referent for the group of politicians they were rating (which could range from local, ward-boss politicians to

*This research was supported in part by a grant from the Research Council, Rutgers University. Requests for reprints should be mailed to the author, Department of Psychology, 73 Easton Avenue, Rutgers, The State University, New Brunswick, N.J. 08903. national figures) rather than their evaluation of politicians per se. Although the data from Asch's study were equivocal on this point, based on interview data from a small sample of people, the explanation is still in wide circulation (Morgan \& King, 1966; Wheeler, 1970). Certainly the explanation is tenable, but the point needs further research. The following study is designed to investigate the attitude change vs restructuring interpretations of the influences of normative information on judgmental processes.

\section{METHOD}

Ninety-seven undergraduates from introductory psychology classes at a large state university were tested in groups of approximately 20 on two occasions. In the first session, Ss rated professions without exposure to alleged group norms; 2 weeks later they did the tasks again after exposure to false information on how a large group of others ranked politicians.

At the first testing, Ss were given handwritten duplicated sheets listing 10 professions to be ranked. The $E$ explained that a secretary had forgotten to type the stencil, and the material had to be improvised. He directed them to rank the professions from 1 through 10 on the attributes of intelligence required and social usefulness of the professions. Then Ss rated five of the professions (business, journalism, music, politics, and teaching) on three pairs of evaluative, polar adjectives, using a 7-point scale.

At the second meeting, Ss were given a stenciled copy of the professions ranking sheet. The $E$ said that some of the people had not followed the directions at the first session and apologized for presenting unclear directions, pointing out that the secretary had finished the stencil and that the directions were typed on the sheet before them. The Ss followed along on their sheets while E read the directions aloud.

Five groups were tested: four of the groups were instructed that another, large, group had ranked the professions and that they had ranked politics 10th (last) on both intelligence required and social usefulness. The prestige of the source was manipulated by attributing the bogus data to students from Harvard University for high prestige, to students from the University of Illinois for equal prestige, and to students from an unnamed junoir college in Illinois for low prestige; no source was listed for the control group. The fifth group received no norms and served as an additional control group. Preliminary work had established significant differences among the three college groups for prestige attributed by college students.

The Ss rated the professions on evaluative polar adjectives for a second time, and after the booklets were collected, a third measure was introduced. The Ss indicated their referent for the rankings of the following professions: business, journalism, music, and politics. A typical format was:

When you rated the profession politics for intelligence required and social usefulness, which group of politicians did you use for your reference?

Men who hold local political offices

Men who hold political offices at a state level

Men who hold political offices at a national level

Politicians in general

Finally, E asked the groups what they thought the experiment was about. The Ss responded to the following open-ended questions: "Why did the experimenter want you to rank the 
professions for intelligence required and social usefulness?" "Why did the experimenter want you to rate some professions between polar adjectives (severe-lenient)?" In addition, space was provided with the heading, "What do you believe was the purpose of this experiment?" Ss were debriefed after all groups had been tested.

\section{RESULTS}

An analysis of variance demonstrated that there were no significant differences among the five groups for the initial rankings of intelligence required or social usefulness of politics $(p>.20)$. Similarly, there were no significant differences for the initial evaluative ratings on the polar adjective scales $(\mathrm{p}>.20)$.

Two judges independently categorized the responses to the open-ended questions regarding the purpose of the individual tasks and the experiment. Responses could have been judged as (1) suspicious, (2) uncertain of whether S was suspicious, and (3) not suspicious. In all cases, both judges rated the responses aqs not suspicious.

There was a significant difference between the control groups and the groups receiving norms attributed to college students, indicated by a planned comparison of means, for change in the rankings of intelligence required $(\mathrm{p}<.05)$. There were no significant differences between the means of the two control groups and no significant differences among the means for the three college-norm groups. These means are given in Table 1 . No significant differences were found among the means for change in social usefulness ratings.

Because of a lack of time, the second set of ratings on the evaluative polar adjectives were not collected from the control group which received information of how another group rated politics. Considering the absolute value of the change in the evaluative ratings, there was a significant effect between the three college-norm groups and the control group, as indicated by a planned comparison of means $(\mathrm{p}<.05)$. The high-prestige group and the equal-prestige group had a larger change than the junior college norm group $(p<.05)$. The mean change of evaluative ratings are given in Table 1.

The reference groups for politicians which Ss said they used following the experimental treatment are summarized in Table 2. Pearson's chi-square test for

Table 1

Mean Devaluation for Rankings of Politics and Absolute Change in Evaluative Ratings as a Function of Treatment Condition

\begin{tabular}{lccccc}
\hline & \multicolumn{5}{c}{ Treatment Conditions } \\
\cline { 2 - 6 } & $\begin{array}{c}\text { Harvard } \\
\text { Norms }\end{array}$ & $\begin{array}{c}\text { U of I } \\
\text { Norms }\end{array}$ & $\begin{array}{c}\text { Jollege } \\
\text { Norms }\end{array}$ & $\begin{array}{c}\text { Nource } \\
\text { Norms }\end{array}$ & $\begin{array}{c}\text { No } \\
\text { Norms }\end{array}$ \\
\hline $\begin{array}{l}\text { Intelligence } \\
\text { Required }\end{array}$ & 2.10 & 1.62 & 2.13 & .93 & .40 \\
$\begin{array}{l}\text { Social } \\
\text { Usefulness }\end{array}$ & 1.20 & 1.44 & 1.04 & .79 & .95 \\
$\begin{array}{l}\text { Evaluative } \\
\text { Ratings }\end{array}$ & 2.00 & 1.90 & 1.50 & - & 1.05 \\
\hline
\end{tabular}

Table 2

Frequency of Referents for Politics Rankings as a Function of Treatment Condition

\begin{tabular}{lccccc}
\hline & \multicolumn{5}{c}{ Treatment Conditions } \\
\cline { 2 - 6 } Referent & Harvard & U of I & $\begin{array}{c}\text { Jr. } \\
\text { College }\end{array}$ & $\begin{array}{c}\text { No } \\
\text { Source }\end{array}$ & $\begin{array}{c}\text { No } \\
\text { Norms }\end{array}$ \\
\hline Local & 1 & 1 & 1 & 0 & 1 \\
State & 0 & 1 & 2 & 1 & 0 \\
National & 3 & 4 & 11 & 4 & 5 \\
In General & 15 & 15 & 6 & 8 & 12 \\
& 19 & 21 & 20 & 13 & 18 \\
\hline
\end{tabular}

Note $-\chi^{2}=15.07$, n.s.

associations did not approach significance for differences among the referents used in ranking politics by members of the five groups. In fact, the differences between the treatment conditions and the control group are in the opposite direction from those suggested by the restructuring hypothesis.

\section{DISCUSSION}

The results of this study on the dynamics of the judgmental processes can be summarized as change in rankings, accompanied by change in the evaluation of politics, without a restructuring of the situation. The finding of little difference in conformity toward the norms among the three prestige treatment groups seems to indicate that the varying prestige among the three institutions had no effect; the norms from each served primarily as peer judgments.

The absolute change of the mean on the evaluative scales is taken to indicate that some attitude change occurred following changes in rankings of politicians. The findings of this study do not support Asch's position on restructuring the situation. The most obvious difference between the two studies is methodological. The objective assessment procedure of the present study is an improvement over the interview procedure. Given the tenuous foundation of most evaluative judgments, it does seem reasonable that attitudes can be altered "merely" by alleged peer-group norms.

An interesting finding in this study was the significant conformity effect found for intelligence required but not for social usefulness rankings. These results can be explained by considering the criteria upon which Ss judge these two attributes. Intelligence required for politics is an abstract dimension for which individuals have no good method of assessment, while social usefulness of politics has many objective standards upon which to form and maintain a judgment.

A greater number of concrete associations exist between politics and social usefulness (e.g., establish laws, maintain roads, legislate taxes, etc.) than between politics and intelligence criteria. Influence on judgmental processes resulting from normative information is postulated to be inversely related to the number of associations as well as the importance of associations which anchor the initial opinion. From this, one would predict that if false norms were given for a profession like accounting, change would be greater for social usefulness than for intelligence required, because there are many associations linking accounting with intellectual behavior (i.e., skills in mathematics) and fewer associations linking accounting with social usefulness. For a profession that has many important associations with both rated attributes, such as medicine, one would predict that resistance to change in judgments would be great for both intelligence required and social usefulness. Thus, the postulate is amenable to an empirical investigation. 


\section{REFERENCES}

Asch, S. E. The doctrine of suggestion, prestige, and imitation in social psychology. Psychological Review, 1948, 55, 250-276.

Asch, S. E., Block, H., \& Hertzman, M. Studies in the principles of judgments and attitudes: II. Determination of judgment by group and by ego standards. Journal of Social Psychology, 1940, 12, 433-465.
Morgan, C. T. \& King, R. A. Introduction to psychology. (3rd ed.) New York: McGraw-Hill, 1966.

Wheeler, L. Interpersonal influence. Boston: Allyn \& Bacon, 1970.

(Received for publication April 2, 1973.)

\section{A replication of Bransford and Franks' (1971) "The abstraction of linguistic ideas"*†}

\author{
MURRAY SINGER \\ Carnegie-Mellon University, Pittsburgh, Pa. 15213
}

Experiment II of Bransford \& Frank's (1971) "The Abstraction of Linguistic Ideas" was replicated in as great a detail as the description of the original procedure would permit. The present results are almost identical to those of Bransford and Franks: Ss frequently reported recognizing new sentences derived from the same complex ideas as sentences heard during acquisition, and their level of confidence in their reports of recognition increased as the complexity of the test sentences increased. These findings enhance Bransford and Franks's conclusion that Ss integrate complex semantic information as presented in related but nonconsecutively experienced sentences, and do not simply memorize the exact sentences which they have heard. The procedures seem appropriate for use in the investigation of other hypotheses concerning semantic memory.

One characteristic of psychological studies concerning memory, both semantic and nonsemantic, has been an emphasis upon one-to-one correspondence between experience and memory storage. Bransford \& Franks (henceforth B-F) (1971), however, have conducted a series of studies that stress the integrative functions of semantic memory. They attempt to show that in attending to linguistic material, primary concern is not with the precise words or sentences employed, but rather with the wholistic ideas that may result from groups of sentences as well as single ones.

In the recognition phase of Experiment II of B-F (1971), Ss heard new sentences that were derived from the same complex ideas as the sentences that they had encountered in acquisition. The Ss' level of confidence in their "recognition" of these new sentences increased monotonically as the complexity of the test sentences increased, except that Ss almost uniformly rejected those sentences (NONCASES) which conflicted with the ideas expressed in the corresponding complex idea. The authors concluded that these results reflected the fact that the more complex of the recognition sentences more completely exhausted the relations embedded in the integrated, wholistic ideas stored by the Ss. The

*This research was supported by Grant $\mathrm{MH}-07722$ from the Public Health Service, National Institiue of Mental Health.

$t$ I sponsor the enclosed paper and accept full editorial responsibility for it. William Chase. present study attempts to replicate Experiment II of B-F (1971).

\section{METHOD}

Although the methods employed in this study approximate closely those of B-F, they will be briefly outlined here.

\section{Subjects}

The Ss were 13 men and 1 woman enrolled in a section of introductory psychology at Carnegie-Mellon University. The Ss participated in this study in partial fulfullment of a course requirement.

\section{Verbal Materials}

The verbal materials consisted of Idea Sets E, F, G, and $\mathrm{H}$ of B-F. The sentence corresponding to Complex Idea $E$, for example, was The scared cat running from the barking dog jumped on the table. This sentence could be analyzed into four underlying propositions (ONES): The cat was scared; The cat was running from the dog; The dog was barking; The cat jumped on the table. It was also possible to recombine the ONES to form two- (e.g., The scared cat was running from the dog) and three- (e.g., The scared cat was running from the barking dog) idea sentences (TWOS and THREES, respectively). The original sentence was referred to as a FOUR.

The acquisition list consisted of six sentences from each of the four complex ideas: two each of THREES, TWOS, and ONES. The order of the 24 sentences was random, with the constraints that (1) in successive sequences of four sentences, there was one sentence from each idea set; and (2) that no two consecutive sentences were from the same idea set.

The recognition list consisted of 30 sentences, shown in Fig. 1 and Table 1: 6 sentences derived from each complex idea (one FOUR, one THREE, two TWOS, and two ONES), and 6 noncase sentences, in which were embedded ideas that violated the relations expressed in acquisition (see Table 1). None of the sentences in this list had occurred in acquisition. Each successive group of five sentences contained one sentence from each idea set plus one NONCASE, and no two consecutive sentences were derived from the same complex idea.

\section{Procedure}

The Ss were separated into two groups for the purpose of counterbalancing the order of presentation of the recognition sentences. There were nine Ss in Group I and five in Group II, and the two groups were tested separately.

\section{Acquisition}

The Ss were told that their task was to answer simple questions about sentences. After reading each sentence, the E held up a sheet of paper showing four colored scribbles which the Ss were to "read" aloud in unison. This was intended to insure that the Ss were holding the sentences in memory for at least a few seconds. The $E$ then read an elliptical question concerning the preceding sentence, and the Ss wrote down their answers. For example, after reading The cat jumped on the table, the E might ask, What did, Did what, or Where? 